\title{
GROWTH AND MIGRATION OF HEADCUT IN HETEROGENEOUS SOIL STRATUM
}

\author{
Ashis Kumar DEY1, Tetsuro TSUJIMOTO ${ }^{2}$ and Tadanori KITAMURA 3 \\ ${ }^{1}$ Student Member of JSCE, Postgraduate Student, Dept. of Civil Engineering, Nagoya University \\ (Furo-cho, Chikusa-ku, Nagoya 464-8603, Japan) \\ ${ }^{2}$ Member of JSCE, Dr. of Eng., Professor, Dept. of Geo- \& Environmental Engineering, Nagoya University \\ ${ }^{3}$ Member of JSCE, Dr. of Eng., Research Associate, Dept. of Geo- \& Environmental Engineering, Nagoya University
}

\begin{abstract}
Flume experiments were conducted to investigate the headcut erosion process in heterogeneous soil stratum. A composite fill was prepared on flume bed composed of coarse sand at bottom and PVC fine particle at top. Adhesive color spray applied on the top surface resisted the surface erosion as well as ensured the headcut development. The effects of hydraulic and geometric condition on headcut migration speed, unaffected by downstream deposition, were analyzed. The experimental result showed the plunge pool morphology remained unchanged with time for a given flow discharge. The migration speed increased with flow discharge and headcut height. Power functions were introduced to correlate the migration speed, flow discharge and headcut height. A conceptual model was introduced to explain details of the headcut migration process. The result of conceptual model reasonably agreed with the experimental data.
\end{abstract}

Key Words : Headcut, migration speed, heterogeneous soil, plunge pool erosion, conceptual model, overland flow, composite fill

\section{INTRODUCTION}

Headcut erosion has long been research focus and recently it has been a major concern because of uncertainty in its formation and development process. The accelerated erosion drastically changes the river landscape and causes sever impacts on global environment.

Several studies on headcut erosion have been done since long. Geomorphologists have explained migrating headcuts in relation to rill incision, drainage network development. Engineers have examined headcut erosion in relation to scour process and sediment detachment. Lewis ${ }^{1)}$ investigated the upstream migration of a preformed headcut in muddy sand material and noted that headcut height decreased with migration distance. Holland and Pickup ${ }^{2)}$ investigated headcut development in stratified sediment composed of cohesive and non-cohesive layers and noted the requisite stratification of the maintenance of a stepped knickpoint during migration. Begin et al. ${ }^{3)}$ initiated degradation by lowering the water level at flume outlet and observed headcut development. They found both size and migration rate of headcut decreased as it migrated upstream. Stein et al. ${ }^{4)}$ investigated scour processes using preformed steps in cohesive soils. They formulated a jet impingement model to predict scour hole development and mode of headcut migration. Robinson ${ }^{5)}$ investigated the migration characteristics and failure mechanics of preformed headcuts in cohesive materials and examined the roles of overfall height and flow discharge in headcut migration. He highlighted the significant impact of material characteristics, especially soil water content, on sediment erodibility and rates of headcut migration. Jia et al. ${ }^{6}$ ) investigated the scouring process in a plunge pool of uniformed loose bed materials due to impinging jet. They developed a numerical model, in which both shear stress and lift force had been taken into account, to evaluate the plunge pool erosion. Bennett et al. ${ }^{7)}$ examined headcut development in cohesive soil. They observed that the scour hole remained unchanged as the headcut migrated upstream. The sediment load was deposited downstream of the migrating headcut, and its slope depended weakly on flow discharge. Dey et al. ${ }^{8)}$ examined the evolution of preformed headcut in non-cohesive soil and noted that a 
reduction in bed slope downstream of a migrating headcut caused a reduction in migration speed.

In spite of these studies, little information exists on the processes of headcut migration and soil erosion, variation of plunge pool morphology, mechanics of headcut erosion, and the effect of flow discharge and headcut height. Headcut erosion resulting from concentrated overland flow sometime causes the cutoff across the meander neck ${ }^{9}$, which changes the river landscape suddenly. The flood plain often composed of stratified soil layers, while most of the previous researches were concentrated on headcut erosion in homogeneous cohesive soils. The knowledge of headcut erosion process in homogeneous cohesive soil is rarely applicable for the stratified soil layers of flood plain. The main objective of the present study is to improve general understanding of headcut erosion process in a noncohesive, heterogeneous soil layers. Flume experiments have been conducted for different hydraulic and geometric conditions to investigate the effect of flow discharge and headcut height on headcut migration in non-cohesive heterogeneous soil.

\section{EXPERIMENTAL INVESTIGATION}

\section{(1) Set-Up and Procedure}

All experiments were conducted in a $20 \mathrm{~m}$ long and $15 \mathrm{~cm}$ wide laboratory flume. The glass-made side-wall with a superimposed grid system of the flume provided us an opportunity to observe the detail scouring process in a plunge pool, and its downstream conditions as well. During experimental runs, a digital video camera mounted on a tripod of a movable carriage recorded details of erosion process such as position and morphology of plunge pool, overland flow depth, and the angle of overfall jet with sufficient accuracy. Flow discharge was controlled by an adjustable inlet valve and monitored through a digital display-meter. Water was fed initially into an inlet tank, which acted as a reservoir for damping turbulence and controlling the flow discharge into the test section. The lower part of flume bed was filled by sand of uniform diameter $0.88 \mathrm{~mm}$ while the upper part was filled by poly vinyl chloride (PVC). The diameter and specific gravity of PVC were $0.15 \mathrm{~mm}$ and 1.3 , respectively. The test section of the flume bed was connected with a wooden false bed at its upstream. A movable point-gauge was used to measure the downstream water surface and bed elevation at regular intervals during experimental runs. The inclination of flume bed was $0.2 \%$ for all experiments. Figure 1 shows the schematic diagram of the experimental set-up. Results of 9 tests are reported in this paper.

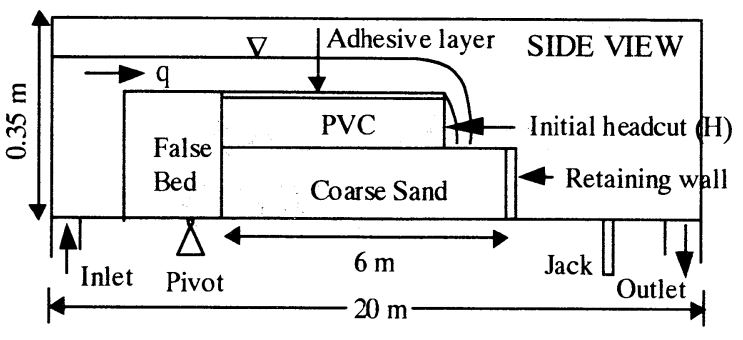

Fig.1 Schematic diagram of experimental set up

Table 1 Experimental conditions

\begin{tabular}{|c|c|c|c|c|}
\hline \multirow[t]{2}{*}{$\begin{array}{c}\text { expt. } \\
\text { no. }\end{array}$} & \multicolumn{2}{|c|}{$\begin{array}{l}\text { fill thickness } \\
\text { (m) }\end{array}$} & \multirow{2}{*}{$\begin{array}{c}\text { unit } \\
\text { discharge } \\
q\left(\mathrm{~m}^{2} / \mathrm{s}\right)\end{array}$} & \multirow{2}{*}{$\begin{array}{c}\text { headcu } \\
\text { height } \\
H(\mathrm{~m})\end{array}$} \\
\hline & sand & PVC & & \\
\hline R-1 & \multirow{9}{*}{$\begin{array}{l}0.10 \sim \\
0.15\end{array}$} & 0.020 & \multirow{5}{*}{0.0069} & 0.020 \\
\hline R-2 & & 0.035 & & 0.035 \\
\hline R-3 & & 0.050 & & 0.050 \\
\hline R-4 & & 0.065 & & 0.065 \\
\hline R-5 & & 0.080 & & 0.080 \\
\hline R-6 & & \multirow{4}{*}{0.050} & 0.0031 & \multirow{4}{*}{0.050} \\
\hline R-7 & & & 0.0050 & \\
\hline R-8 & & & 0.0117 & \\
\hline R-9 & & & 0.0155 & \\
\hline
\end{tabular}

\section{(2) Fill Preparation}

Loose sand was filled firstly and packed incrementally in several layers to reach the designated height. A gentle compaction was applied to assure a uniform density. The section was made flooded to remove all air-void from the sand deposition. PVC paste was prepared separately by adding the sufficient amount water until desired workability appeared. The PVC paste was then damped on previously packed sand layer of the flume bed. Placing of PVC was also done incrementally in several layers to reach the designated height. The surface of PVC layer was made level with the help of leveling instruments and by the application of water. A vertical initial headcut was set near the downstream end of the test section. Adhesive color spray $\left(4 \times 10^{-4} \mathrm{~m}^{3} / \mathrm{m}^{2}\right)$, that caused the inter-particle bond, was applied on the fill surface to make a surface-seal. The sealed surface resisted the surface erosion and thus ensured the development of headcut. About $24 \mathrm{hr}$ was allowed before experimental run to dry the surface layer completely. The different experimental conditions are tabulated in Table-1.

\section{RESULTS AND DISCUSSIONS}

Headcut growth and development were the same for all runs. After an initial period of bed adjustment, a steady state condition appeared. 
Headcut of almost same geometry migrated upstream at a constant speed. A photograph digitized from the video camera is shown in Fig.2 to provide a real image of the experimental runs. In most runs, headcut migration continued for a distance of $4 \mathrm{~m}$ or more, or more than $90 \mathrm{~min}$.

\section{(1) Plunge Pool Erosion}

At beginning of the experiments the overland flow of known discharge was released onto the test section. The overland flow discharge $(Q)$ ranged from 1.7 to $8.4 \mathrm{~m}^{3} / \mathrm{hr}$, where the flow depth at brink $\left(h_{b}\right)$ of the approach flow ranged from 0.007 to $0.02 \mathrm{~m}$. The overland flow passed over the preformed headcut and the flow impinged the surface just downstream of the initial step. The impinging jet caused accelerated erosion, which created a plunge pool. This plunge pool gradually developed, enlarged and migrated upstream with time. The location of initial scours depended on flow discharge and jet angle. At high discharges the intense scour occurred at several centimeter downstream of headcut location, while at low discharge this occurred relatively closer to the headcut step. However, as scour process proceeded, the plunge pool became wider and deeper. Concurrently, erosion initiated at the toe of headcut step and then gradually proceeded upstream as the plunge pool moved toward the headcut. The plunge pool created in the bottom coarse sand layer soon made an overhang for the upper PVC layer. The overhang length increased with time. Once the critical length, which made the system unbalanced, appeared the top PVC layer suddenly failed and caused a step migration of the headcut. As the top PVC layer was composed of very fine particles, the broken particles immediately transported downstream as wash load. After the step migration of headcut the plunge pool started to readjust and repeated the same for the further step migration. For a particular experimental run the morphology of the headcut did not vary significantly during migration once the steady state condition achieved (Fig.3). Deviations from the mean headcut profile at any given time were only because of spatial and temporal variations in boundary conditions such as bulk density, packing efficiency, sidewall effect and strength of surface seal. Figure 4 shows the time variation in plunge pool shape $\left(L_{s}\right.$ and $\left.D_{s}\right)$ for a typical run. However, it was observed that the shape of the plunge pool varied with the unit flow discharge (Fig.5). Both $L_{s}$ and $D_{s}$ increased with flow discharge. On the other hand, $D_{s}$ and $L_{s}$ remained almost unchanged with headcut height (Fig.6).

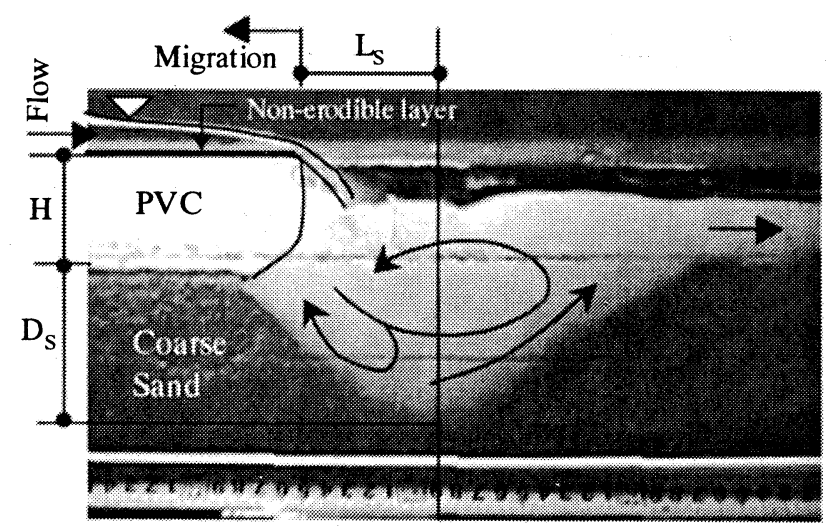

Fig.2 Photograph shows the flow structure in plunge pool (R-7 at $\mathrm{t}=73 \mathrm{~min}$ )

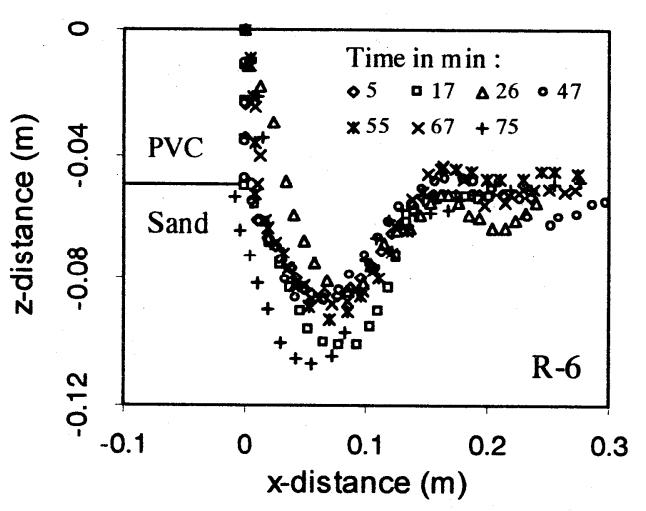

Fig.3 Time variation in plunge pool shape

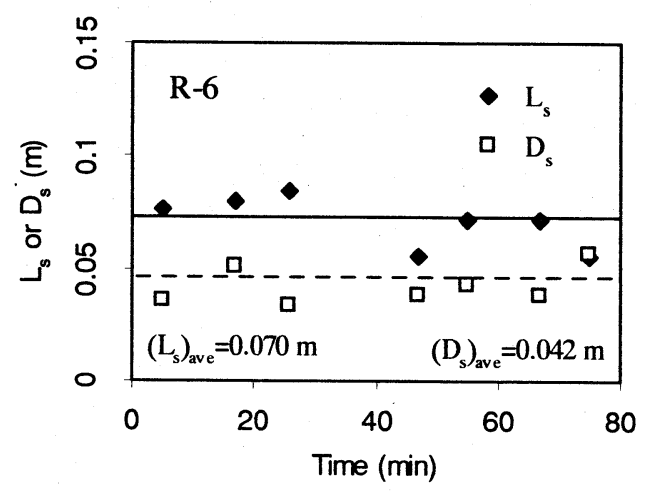

Fig.4 Time variation in $L_{s}$ and $D_{s}$

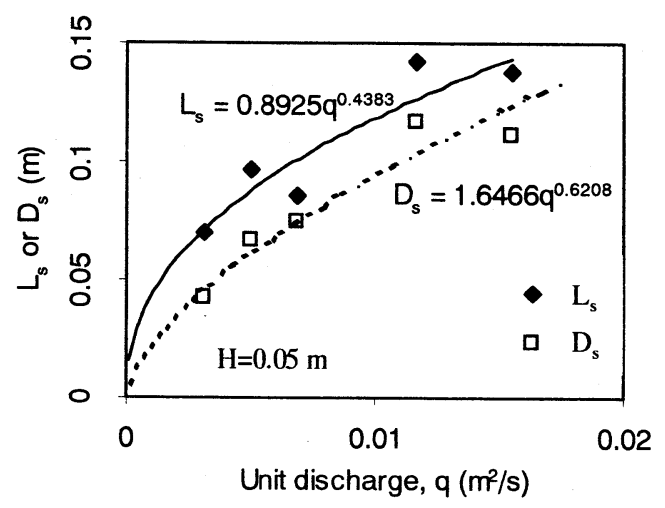

Fig.5 Variation in $L_{s}$ and $D_{s}$ with flow discharge 


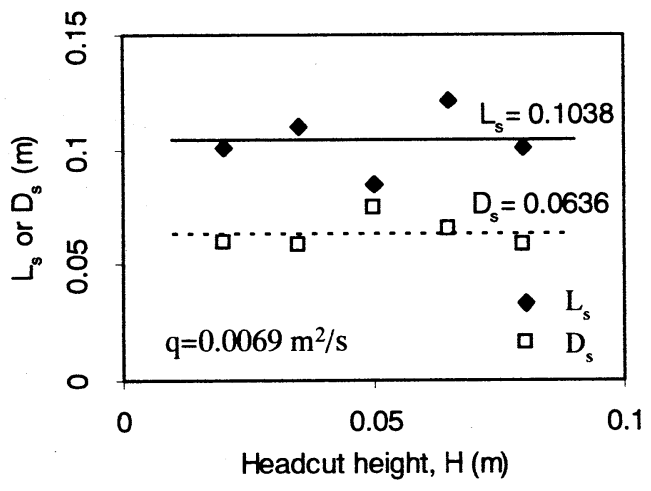

Fig.6 Variation in $L_{s}$ and $D_{s}$ with headcut height

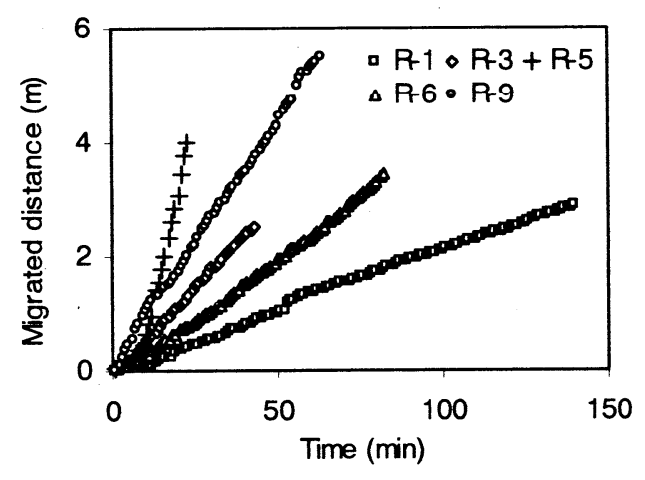

Fig.7 Position of headcut with time

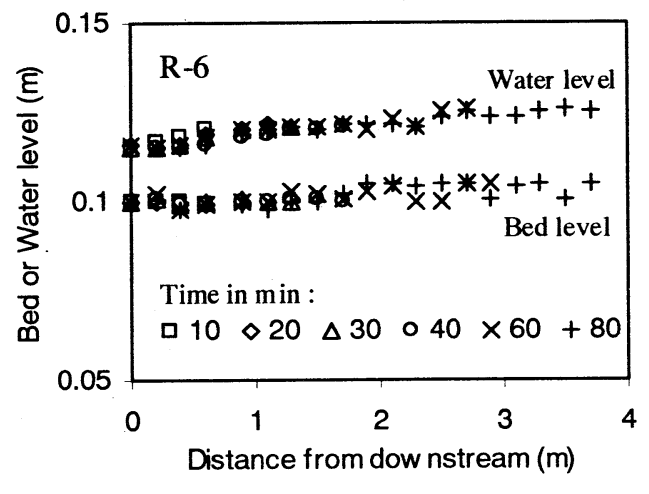

Fig.8 Downstream water and bed level with time

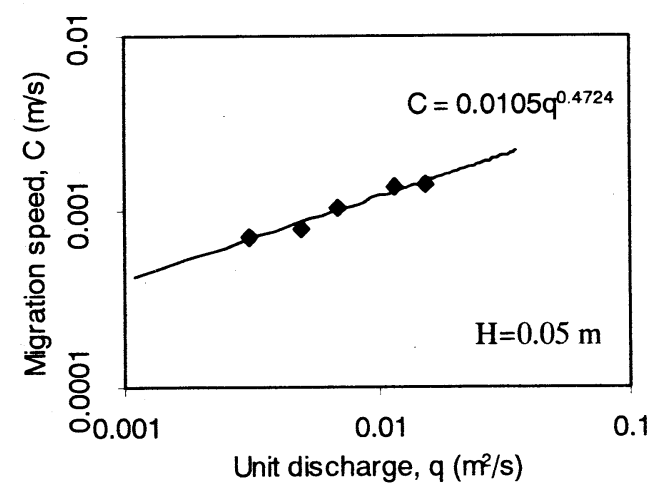

Fig.9 Migration speed with flow discharge

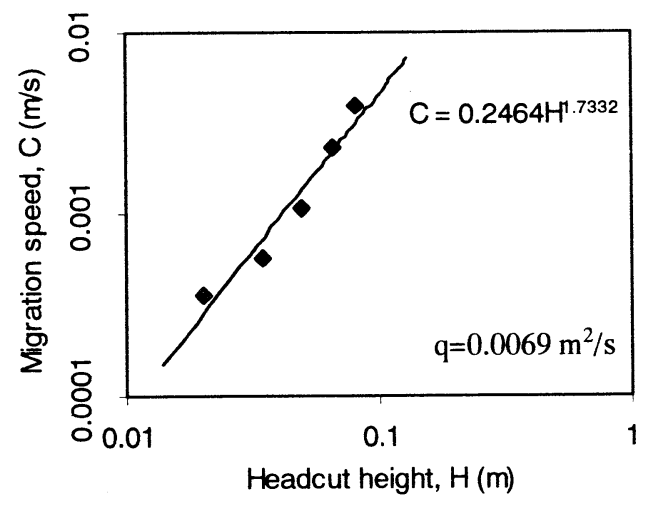

Fig.10 Migration speed with headcut height

\section{(2) Headcut Migration}

After the initial period of growth and adjustment, the headcut brinkpoint migrated upstream in a gradual and liner fashion through time (Fig.7). The headcut migration speed was constant for a particular run, ranging from 0.36 to $3.92 \mathrm{~mm} / \mathrm{s}$ depending on flow discharge and headcut height. All of the detached PVC fine particles were transported as wash load and no deposition was observed at downstream of headcut (Fig.8). The downstream bed elevation was fixed in place by the soil retaining wall located at most downstream end of the test section. To investigate the role of unit flow discharge $(q)$ and headcut height $(H)$ on headcut migration speed $(C)$, it was noticed that $C$ increased with both $q$ and $H$, where the effect of $H$ was found more significant. Figure 9 and 10 show the effect of $q$ and $H$ on migration speed.

\section{(3) Flow Pattern in Plunge Pool}

The time mean flow pattern in plunge pool obtained from the video recording is shown in Fig.2. Uniform flow accelerated at brink and then entered into the plunge pool. The jet entry angle was about $31^{0}$ at low flow rates and $63^{\circ}$ at high flow rates. The overfall nappe remained nonventilated at all low flow rate. The diffuse jet impinged the bed just around the maximum scour depth. This general flow pattern did not vary either during headcut migration or with increasing flow discharge.

\section{CONCEPTUAL MODEL}

The process of headcut erosion includes jet impingement scour, formation and development of plunge pool in bottom sand layer, cantilever failure of top PVC layer and subsequently step migration of headcut. A model is, therefore, proposed to relate the above things and to describe the precise mechanism of headcut erosion process in the present study. The free jet, unaffected by boundary, enters 
the plunge pool with an initial thickness $\left(y_{0}\right)$ and uniform velocity $\left(U_{0}\right)$ at an angle $\alpha$ (Fig.11). These values can be known analytically form the concepts of free fall jet characteristics. The plunge pool becomes wider and deeper with time by the impact of flow jet. This process soon makes an overhang for the top PVC layer. Once the critical cantilever length appears, the mass failure of the top layer causes a step migration of headcut. However, the migration speed can be simply known by the following equations:

$$
\begin{aligned}
& C=\frac{L_{c}}{T_{S}} \\
& T_{S}=\int_{D_{0}-D_{f} / 2}^{D_{0}+D_{f} / 2}\left(\frac{d t}{d D}\right) d D
\end{aligned}
$$

where $L_{c}=$ the critical cantilever length of the PVC layer to collapse and can be defined as $\left(D_{f} / \tan \phi\right)$; $\phi=$ angle of repose of sand; $T_{s}=$ time required to attain the $L_{c} ; D_{0}=$ time averaged plunge pool depth measured from water surface $\left(D_{s}+h_{d}\right)$; $h_{d}=$ downstream water depth; $D_{f}=$ average fluctuation in plunge pool depth. The rate of scour $(d D / d t)$, which is governed by the incoming flow jet, is the main factor to control the migration speed and can be determined by equating sediment continuity with the excess shear stress mentioned as ${ }^{4)}$

$$
\frac{d D}{d t}=A\left(\tau-\tau_{c}\right)^{m}
$$

where $\tau=$ maximum shear stress acting on the bed in impingement region, which appears at jet centerline; $\tau_{c}=$ critical shear stress of the bed material at jet centerline, which is quite different from the critical shear stress in usual flow conditions; $A$ and $m$ are the empirical constants. The value of $m$ is from 1 to 1.5 (Stein et al. $\left.{ }^{4}\right)$. The maximum shear stress $\tau$ can be related to maximum centerline velocity $U$ in the impingement region by introducing a coefficient of friction $\left(C_{f}\right)$ as follows

$$
\tau=C_{f} \rho U^{2}
$$

where $\rho=$ mass density of water. The jet spreads laterally and diffuses throughout the surrounding water decreasing in average velocity. The zone in which the centerline velocity remains constant at $U_{0}$ defines the potential core, of depth $D_{p}$ measured from the water surface and beyond this distance the velocity $U$ is reduced by diffusion and can be expressed as ${ }^{10)}$

$$
\begin{array}{ll}
U=U_{0} & \text { for } D \leq D_{p} \\
U=U_{0} C_{d} \sqrt{\frac{y_{0} \sin \alpha}{D}} & \text { for } D>D_{p}
\end{array}
$$

where $C_{d}=$ diffusion constant $(2.28$ to 2.47$)$. The shear stress $\tau$ decreases beyond the potential core until it approaches to $\tau_{c}$. The condition when $\tau$

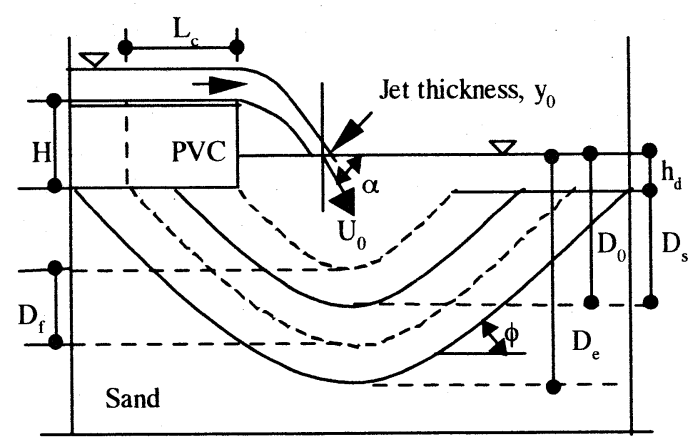

Fig.11 Plunge pool details

reaches to $\tau_{c}$ is assumed as equilibrium and the corresponding equilibrium scour depth $\left(D_{e}\right)$ can be described as

$$
D_{e}=C_{d}^{2} C_{f} \rho U_{0}^{2} \frac{y_{0} \sin \alpha}{\tau_{c}}
$$

However, Eq.(3) can be rewritten in the following forms with the help of Eq.(4), (5), (6) and (7)

$$
\begin{aligned}
& \frac{d D}{d t}=a U_{0}^{2 m}\left[1-\frac{b}{D_{e}}\right]^{m} \quad \text { for } D \leq D_{p} \\
& \frac{d D}{d t}=a b^{m} U_{0}^{2 m}\left[\frac{1}{D}-\frac{1}{D_{e}}\right]^{m} \text { for } D>D_{p}
\end{aligned}
$$

where $a=A C_{f}^{m} \rho^{m}$ and $b=C_{d}^{2} y_{0} \sin \alpha$. Difficulties may arise in calculation of $D_{e}$ through Eq.(7), as it includes $C_{f}$ and $\tau_{c}$ terms. No perfect description exists yet for the prediction of these two terms in the plunge pool. Most recently Hoffmans ${ }^{11)}$ proposed a formula to determine $D_{e}$ in plunge pool as

$$
\begin{aligned}
& D_{e}=p \sqrt{\frac{y_{0} U_{0}^{2} \sin \alpha}{g}} \\
& p=\frac{20 v^{2 / 9}}{d_{90}^{1 / 3}(\Delta g)^{1 / 9}} \quad \text { (but not less than 2.9) }
\end{aligned}
$$

where $g=$ acceleration due to gravity; $v=$ =kinematic viscosity; $d_{90}=$ sediment size; $\Delta=$ relative density $=\left(\rho_{s}-\rho\right) / \rho ; \quad \rho_{s}=$ mass density of sediment. Eq.(10) was developed analytically based on momentum balance within plunge pool, in which a classical approach of mechanics were considered to evaluate the normal and shear stress exerted along the bed of the scour hole. On the other hand Eq.(11) is an empirical relationship based on more than 200 flume experiments.

The experimental result shows that at steady state condition the plunge pool depth and its fluctuation zone remain beyond the potential core (Table 2). So the constant scour rate at time averaged plunge pool depth as Eq.(9) and its coupling with Eq.(1) and (2) yield the following equation to predict the headcut migration speed: 
Table 2 Parameters in different experimental conditions

\begin{tabular}{|c|c|c|c|c|c|c|c|}
\hline $\begin{array}{l}\dot{\Phi} \\
\text { 离 } \\
\text { 离 }\end{array}$ & 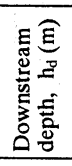 & 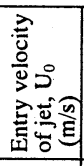 & 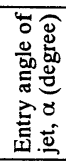 & 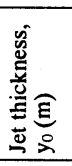 & 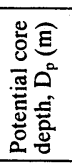 & 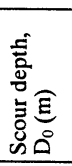 & 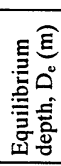 \\
\hline $\mathrm{R}-1$ & .020 & .678 & 31 & .0101 & .0319 & .0794 & .111 \\
\hline$R-2$ & .026 & .800 & 43 & .0086 & .0361 & .0834 & .140 \\
\hline $\mathrm{R}-3$ & .023 & .989 & 54 & .0069 & .0344 & .0983 & .169 \\
\hline R-4 & .025 & 1.11 & 58 & .0062 & .0322 & .0900 & .184 \\
\hline R-5 & .021 & 1.27 & 63 & .0054 & .0295 & .0803 & .200 \\
\hline R-6 & .019 & .936 & 62 & .0033 & .0178 & .0614 & .115 \\
\hline R-7 & .022 & .953 & 57 & .0052 & .0268 & .0887 & .143 \\
\hline R-8 & .028 & 1.03 & 48 & .0113 & .0511 & .1444 & .215 \\
\hline R-9 & .037 & 1.02 & 41 & .0152 & .0615 & .1477 & .231 \\
\hline
\end{tabular}
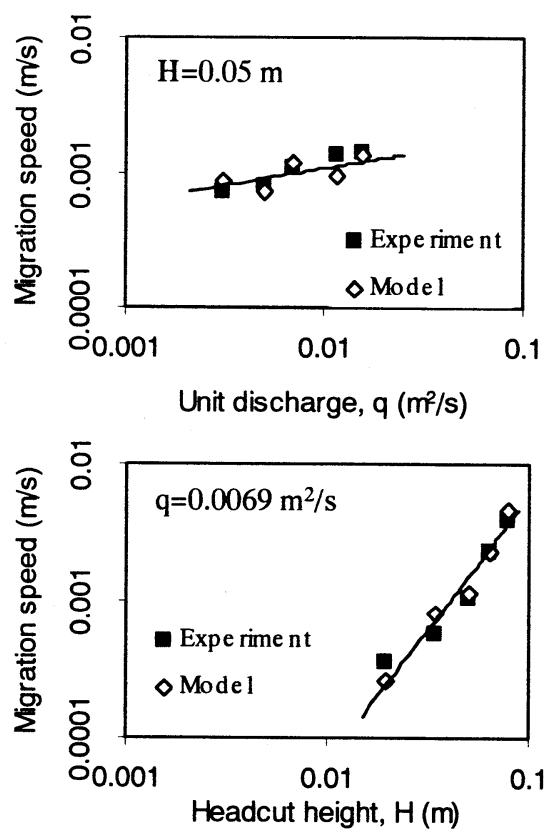

Fig.12 Comparison between experiment and model results

$$
C=\frac{a b^{m} U_{0}^{2 m}}{\tan \phi}\left[\frac{1}{D_{0}}-\frac{1}{D_{e}}\right]^{m}
$$

Solution of Eq.(12) is plotted in Fig.12 with the experimental results, in which the values of different parameters were: $a=0.015, C_{d}=2.47, \phi=35^{\circ}$ and $m=1.5$. The values of $D_{0}$ were obtained experimentally. In fact $D_{0}$ in Eq.(12) also includes the effect of $L_{s}$ in migration speed (Fig.11). A close agreement between model results and experimental data ensures that the proposed model is good enough to predict the headcut migration speed.

\section{CONCLUSION}

Headcut migration process in stratified noncohesive soil, and the effects of flow discharge and headcut height were investigated through laboratory experiments. The migration speed $(C)$ increased with both flow discharge $(q)$ and headcut height $(H)$.
For any given condition, a steady state condition was reached during headcut migration where the plunge pool geometry and rate of migration remained unchanged. The migration process was related to erosion rate of plunge pool. Flow jet impinged on the bed material of the plunge pool, which caused an under scour of top PVC layer. Once the critical cantilever length appeared the mass failure of PVC layer occurred, which caused a step migration of headcut. A model based on scour rate in plunge was proposed to evaluate the headcut migration process. The values of $D_{0}$ in Eq.(12) was obtained from the experimental data. More sophisticated model is needed to describe $D_{0}$ analytically, which is left for the time being as a future extension of this study. However, the proposed model is able to predict the migration speed with sufficient accuracy.

\section{REFERENCES}

1) Lewis, W. V. : Stream through experiments and terrace formation, Geological Management, LXXXI, pp. 241-253, 1944.

2) Holland, W. N. and Pickup, G : Flume study of knickpoint development in stratified sediment, Geological, Society of America Bulletin, Vol. 87, pp. 76-82, 1976.

3) Begin, Z. B., Meyer, D. F. and Schumm, S. A. : Knickpoint migration due to baselevel lowering, Journal of Waterway, Port, Coastal and Ocean Engineering, 106, pp. 369-388, 1980.

4) Stein, O. R., Julien, P. Y. and Alonso, C. V. : Mechanics of jet scour downstream of headcut, Journal of Hydraulic Research, Vol. 31, pp. 723-738, 1993.

5) Robinson, K. M. : Gully erosion and headcut advance, Ph.D Thesis, Oklahoma State University, 1996.

6) Jia, Y., Kitamura, T. and Wang, S.S.Y. : A model for simulating scour processes in a plunging pool of loose bedmaterial, submitted to Journal of Hydraulic Engineering, ASCE, 1999.

7) Bennett, S. J., Alonso, C. V., Prasad, S. N. and Romkens, M. J. M. : Experiments on headcut growth and migration in concentrated flows typical of upland area, Water Resources Research, Vol. 36, No. 7, pp. 1911-1922, 2000.

8) Dey, A. K., Kitamura, T. and Tsujimoto, T. : Headcut erosion affected by downstream deposition, Annual Journal of Hydraulic Engineering, JSCE, Vol. 45, 2001.

9) Gay, G. R., Gay, H. H., Gay, W. H., Martinson, H. A., Meada, R. H. and Moody, J. A. : Evolution of cutoffs across meander necks in powder river, Montana, USA, Earth Surface Processes and Landforms, 23, pp.651-662, 1998.

10)Rajaratnam, N. : Turbulent jets: Development in water science, No. 5, Elsevier Scientific Publishing Co., Amsterdam, The Netherlands, 1976.

11)Hoffmans, G. J. C. M. : Jet scour in equilibrium phase, Journal of Hydraulic Engineering, Vol. 124, No. 4, pp. 430437, 1998.

(Received October 2, 2000) 